\title{
Experimental Testing Of Magneto Rheological Based Automotive Semi Active Suspension System for Two Wheeler
}

\author{
${ }^{1}$ Ajinkya Joshi, ${ }^{2}$ Prashant Narwade \\ ${ }^{1}$ M.E. Student, ${ }^{2}$ Assistant professor, Department of Mechanical Engineering, Dr.Vithalrao Vikhe \\ Patil College Of Engineering, Ahmednagar, India.
}

\begin{abstract}
A system of mechanical linkages, springs, damper that's wont to connect the wheels to the chassis is understood as suspension. it's sometimes done two works-controlling the vehicle's handling and braking for safety and keeping the passengers snug from bumps, vibrations etc. magneto rheological (MR) damper is plays important role to cut back the vibration. Mr fluid has been attracting nice great attention as a result of it will modification its characteristics terribly quickly Associate in Nursingd controlled simply within the presence of an applied flux. These fluids have the power to transmit force during a controlled manner with the assistance of flux, so up their performance particularly in areas controlled fluid motion is needed. If there's a fault within the system, the Mr damper will still operate as a passive damping system among bound performance parameters betting on the off-state characteristics of the Mr fluid within. This work includes, style and development of adaptive magneto rheological (MR) based mostly semi-active suspension for specific automobile application. Its analysis is to be allotted through an experiment and comparison of results with passive suspension.
\end{abstract}

Keywords-Magneto Rheological (MR) Fluid, semi-active damper, Passive damper etc.

\section{INTRODUCTION}

A mechanical system created by several parts that are having motion and vibration. typically motions and vibrations will be helpful however excessive vibration causes discomfort to folks, harm to machines and buildings and wear of machine elements like bearings and gears. The drivers of vehicles throughout square measure exposed to vibration due the unbalanced rotating elements of the machines or by the paved surface unevenness. the largest downside to traveller is that they're exposed to vibrations in an exceedingly frequency vary from virtually zero to $20 \mathrm{hz}$. this kind of discomfort causes that the driving force and passengers to lose concentration, get tired early and when many years it will have dramatic effects on their health . A system of mechanical linkages, springs, damper that's accustomed connect the wheels to the chassis is understood as mechanical system. it's sometimes done 2 works dominant the vehicle's handling and braking for safety and keeping the passengers snug from bumps, vibrations etc. the work of a automobile suspension is to maximise the friction between the tires and therefore the paved surface, to produce steering stability with sensible handling and to confirm the comfort of the automobile passengers. The muffler characteristics square measure represents by the linear average worth of muffler (both rebound and compression strokes), the linear rebound, and therefore the compression strokēs with completely different slopes and actual measurements characteristics. Also, a constant study is winding up to check the impact of mass magnitude relation and stiffness magnitude relation on the vehicle performance. The mass magnitude relation was outlined because the magnitude relation of the unsprung mass to the sprung mass whereas the stiffness magnitude relation was outlined because the magnitude relation of spring stiffness to tire stiffness. the most output from this analysis can get the response in terms of displacement, velocity, acceleration, and forces. These parameters are considering the measure of the stability and ride comfort.

There square measure many passive suspension techniques like elastic materials applications, friction devices, tuned dampers, isolators, impact dampers. elastic materials have long been used for increasing damping in structures. However, they lose their effectiveness in low and warmth environments and degrade over time. therefore there's a necessity of contemporary mechanical system which might operate for a protracted amount of your time and provides ride comfort

\section{LITERATURE REVIEW}

Banna Kasemi et al. [1]., have clarified in the paper entitled "Fluffy PID Controller for Semi-Active Vibration Control Using Magneto-rheological Fluid Damper" that a mostly 
three kinds of control gadgets aloof gadgets, dynamic gadgets and semi-dynamic gadgets. In this paper creator clarifies the semi dynamic control gadgets. Magnetorheological (MR) dampers, variable hole dampers and tuned fluid dampers are instances of semi-dynamic gadgets. In this paper creator led tests to build up the conduct of the MR damper likewise the conduct of MR damper is considered and utilized in actualizing vibration control. The relations between power - relocation and power speed have been built up for the MR damper with differing current. The creator found that power for the upward movement and descending movement of damper cylinder is expanding with current and speed. From the outcomes it is gotten that, power reaction over differing current and removal, can be utilized as MR damper model. Utilizing this model, a controller can control the MR damper's variable damping yield to control the vibration of a vehicle, which gives the travelers better solace.

R.Sundarrajan et al. [2] have clarified in the paper entitled "Execution of Magneto-rheological dampers in guards of Automobiles for diminishing effects during mishaps" that the paper contains actualizing the magneto Rheological guard in the front wheels of the four wheeler, which results into the decrease of the misfortune and misshapening of vehicle during mishap. This paper additionally comprise the fundamental characters and properties of the magneto rheological liquids (MR). In this paper creator examined the exploration consequences of the previous decades in Magneto Rheological liquids and their applications are additionally looked into. It is one of the significant materials utilized by significant specialists in planning parts like brakes, dampers, grips. Additionally the creator clarified Magneto-rheological methods which are utilized to decrease the effects during crash of vehicles.

Martin Orecny et al. [3] have clarified in the paper entitled "Utilization of a magneto-rheological damper and a powerful safeguard for a suspension of a working machine seat" that the paper creator clarified two options of semi dynamic suspensions of a seat of working machine. The first is magneto-rheological damper and the subsequent one is the blend of magneto-rheological damper and dynamic safeguard. In this paper the affectivity of a DA on seat suspended by a MR damper was considered. The adjustment in the seat spring firmness changed about for $3 \mathrm{x}$, however the impact of the applied DA assisted with decreasing the compelling estimations of removals just for $5 \%$.From this paper the creator presumed that the impact of the applied DA is immaterial than the MR dampers since MR dampers lessens the maximal amplitudes to values that are practically unnoticeable for the administrator arranged on the seats.

Sadak Ali Khan et al. [4] have clarified in the paper entitled "Standards, Characteristics and Applications of MagnetoRheological Fluid Damper in Flow and Shear Mode" that the different methods of utilization and qualities of MR liquids are talked about. Scientific displaying of the MR liquid dampers dependent on Bingham plastic model and Herschel Bulkley model are introduced. In this paper creator clarified Magneto-rheological (MR) liquids as their material properties can be tweaked through an applied electro-attractive field. Uncommonly, they are prepared to do reversibly transforming from a straight Newtonian liquid to a semi strong with in a small amount of the milli seconds and the yield quality of this semisolid is controllable.

Bhau K. Kumbhar et al. [5] have clarified in the paper entitled "Amalgamation and portrayal of magnetorheological (MR) liquids for MR brake application" that the Magneto-rheological (MR) liquid innovation can be utilized in different mechanical applications like safeguards, actuators, and so forth. MR liquid is a savvy material whose rheological attributes change quickly and can be controlled effectively in nearness of an applied attractive field. MR brake is a gadget to transmit torque by the shear worry of MR liquid. In this paper creator clarified the synthesization of MR liquid examples which will regularly meet the necessities of MR brake applications. Likewise the creator concentrated on synthesization of different electrolytic and carbonyl iron powder based MR liquids by blending oil as a stabilizer, oleic corrosive as an antifriction added substance and gaur gum powder as a surface covering to diminish agglomeration of the MR liquid.

\section{OBJECTIVES}

1. Study and understand passive and semi-active (MR base) suspension system

2. Design and development of Magneto-rheological damper

3. Investigation of performance of MR base semiactive suspension system comparing with passive suspension system

\section{METHODOLOGY}

1. Study and understand of passive and semi-active suspension system

2. Selection of appropriate damper

3. Selection of suitable magneto-rheological fluid

4. Design and development of magneto-rheological damper

5. Design of circuit

6. Design and development of set-up

7. Testing

8. Result interpretation

9. Conclusion

\section{MAGNETO-RHEOLOGICAL DAMPER}

The dampers or shock absorbers are widely used in automotive vehicles to dissipate the vibration energy of sprung (car body) and un-sprung (wheel) mass below resonance conditions. many sorts of dampers are designed 
to fulfill the comfort and management needs of traveller vehicles.

The automotive shock has been shown to be a very necessary contributor to the ride comfort and road handling of a vehicle. For ride comfort, shock absorbers with a 'soft' setting are needed to dissipate shock energy from the road, whereas a 'hard' setting is needed permanently vehicle handling. These conflicting characteristics of ride comfort and road-holding could be a major challenge to automotive shock absorber design. The standardisation of typical hydraulic shock absorbers usually involves the physical changes of the settings of assorted valves placed within the piston. Also, typical absorbers can have a continuing setting throughout their time period, and therefore won't be able to operate satisfactorily in an exceedingly big selection of road conditions. it's for these reasons that semi-active systemslike adult male dampers have attracted the eye of suspensiondesigner and scientist. mr dampers aren't only advantageousin their ability to produce variable damping forcesto the suspension; they're inherently fail-safe devices froman electronic purpose of read. If there was a fault within the system,the $\mathrm{mr}$ damper will still operate as a passive dampingsystem at intervals bound performance parameters dependingon the off-state characteristics of the mr fluid inside

\section{MR Damper Components}

The studied device (Figure a) consists of a mobile piston inside a fixed cylindrical container (Figure b), which is filled with a electro active fluid of the magneto-rheological type. The piston and the cylinder are made of steel, being that, as it shows the figure $\mathrm{c}$, the piston presents a central rabbet where is inserted a bobbin. The conducting wire of the bobbin passes through an orifice elaborated in the centre of the piston axle (Figure d), thus allowing linking to the external current source. The inferior and superior part of the cylinder was closed by a transparent acrylic cover (Figure e).

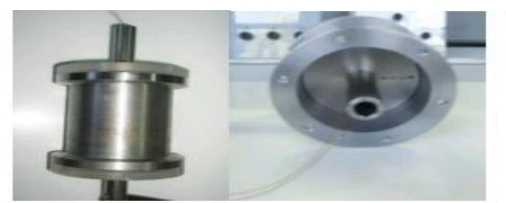

(a)

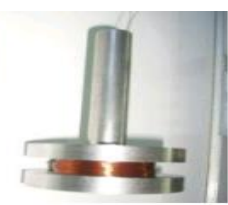

(c)

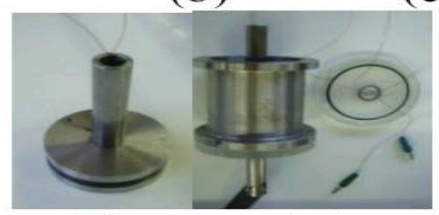

(d)

(e)

Fig. 1 - Damper components: a) Cylinder; b) cylinder interior part with piston inside; c) and d) piston, piston rod and coil; e) acrylic covers.

\section{Configuration and Working of MR Damper}

The damper includes a double-tube configuration consisting of two concentric cylinders. The piston, that is mounted onto the connecting rod, moves up (rebound) and down (compression) on the inside of the tube. The piston divides the damper into two elements, namely: the rebound chamber, that is the space on top of the piston, and therefore the compression chamber, which is the space below the piston. Holes at rock bottom of the tube permit the compression chamber to be a continuous a part of the outer tube. The gas part on the outer cylinder is full of pressurized air. not like single-tube configurations, this double-tube style doesn't need a purpose-made accumulator to compensate for volumetrically changes within the chambers induced by upward and downward motions of the piston. The stroke length of this kind of double-tube style is also generally larger than a similar single-tube assembly.

The mister fluid flows between the rebound Associate in Nursing compression chambers through an rounded gap within the piston. within the annular gap may be a magnetic circuit that's driven by an electromagnet situated within the piston head. The resistance to the flow of the mister fluid through this gap may be controlled by varied the strength of the force field generated by the coils. The force is taken into account to be positive if the rod moves out of the damper body, i.e. once it's in rebound stroke, and it's negative throughout compression.

\section{MAGNETO-RHEOLOGICAL (MR) FLUID}

Magnet- rheological fluids commonly known as MR fluids are suspensions of solid in liquid whose properties changes drastically when exposed to magnetic field. It is this property which makes it desirable to use in different vibration controlling systems.

\section{Working:}

Major constituents of $\mathrm{mr}$ fluid are oil (Mineral and synthetic oil, silicone Oil) and iron particles that vary in percentages per the specifications. the dimensions of magnetic particles is approximate of the order of $1 \mu \mathrm{m}$ to $10 \mu \mathrm{m}$

Iron particles are coated with anti-coagulant materials. once this mix of fluid is in inactive state, it acts as typical natural oil. once field is applied within the vicinity areas of fluids, micro-sized iron particles that ar distributed throughout the fluid create themselves align according to the applied magnetic flux lines. It happens once iron particles moves from one magnetic pole to the opposite and perpendicular to every magnet pole surface.MR fluid may be a noncolloidal suspension of polarisable particles whereas mister fluid sometimes contain carbonyl iron on the order of a number of microns in size, Ferro fluids use nanometre-sized iron chemical compound particles. Ferro fluid particles are too tiny to demonstrate any yield strength; instead they 
have a tendency to be solely interested in and flow toward a field. MR fluids, on the opposite hand, demonstrate terribly high yield strengths once a field is induced, sometimes on the order of twenty to fifty times the strength of ER fluids. With absence of applied field (off state), mister fluids behave as a Newtonian-fluid. Applying AN external field through the fluid activates mister fluids, inflicting the micron-sized particles to make magnetic dipoles on the magnetic lines of force.
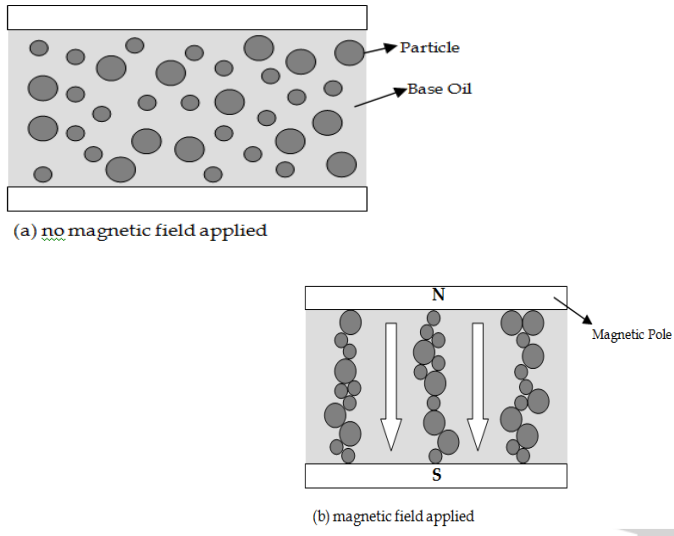

Fig 2. (a) off State Magnetic Fluid particles and (b) Aligned in Applied Magnetic Field

\section{CATIA}

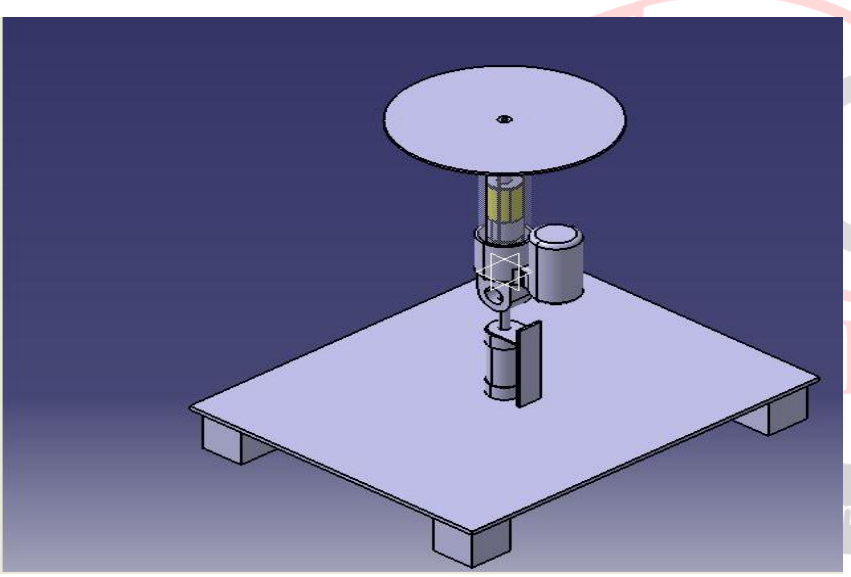

Fig 3 Catia model of Setup

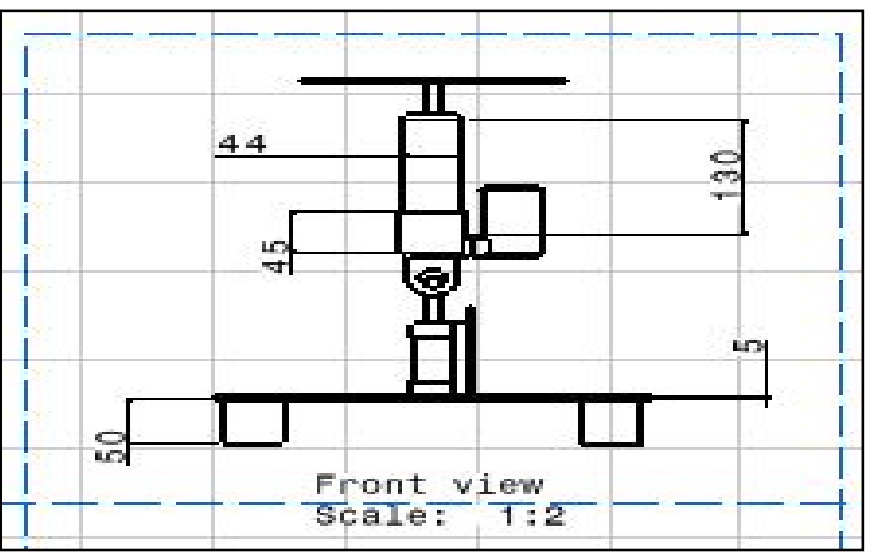

Fig 4 Drafting of MR damping Setup

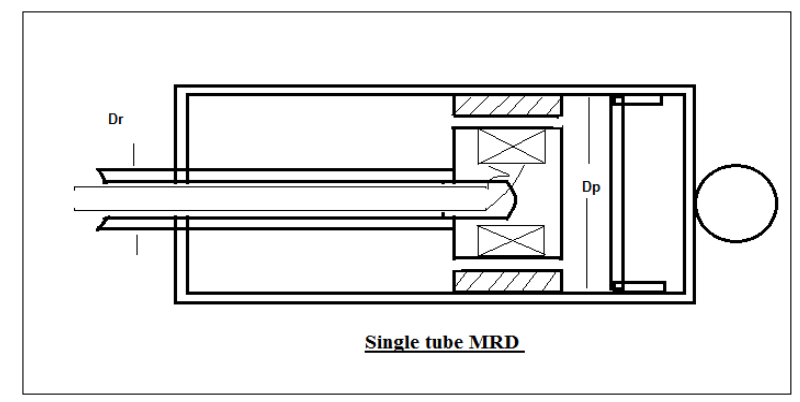

Specification

MR damper length - 130mm

$D_{0}$ - Outer diameter of damper cylinder - $44 \mathrm{~mm}$

$D_{i}$ - Inner diameter of damper cylinder - $43 \mathrm{~mm}$

Piston cylinder - $42 \mathrm{~mm}$

Piston rod - $125 \mathrm{~mm}$

Pneumatic cylinder- $25 * 50 \mathrm{~mm}$

\section{MR FLUID}

\section{Silicone Oil}

A silicone oil is any liquid polymerized siloxane with organic side chains. The most important member is polydimethylsiloxane. These polymers are of commercial interest because of their relatively high thermal stability and their lubricating properties.

\section{Structure}

Like all siloxanes (e.g., hexamethyldisiloxane), the polymer backbone consists of alternating silicon and oxygen atoms (...Si-O-Si-O-Si...). Many groups can be attached to the tetravalent silicon centres, but the dominant substituent is methyl or sometimes phenyl. Many silicone liquids are linear polymers end-capped with trimethylsilyl groups. Other silicone liquids are cyclosiloxanes.

Silicone oils are primarily used as lubricants, thermic fluid oils or hydraulic fluids. They are excellent electrical insulators and, unlike their carbon analogues, are nonflammable. Their temperature stability and good heattransfer characteristics make them widely used in laboratories for heating baths ("oil baths") placed on top of hotplate stirrers, as well as in freezedryers as refrigerants. Silicone oil is also commonly used as the working fluid in dashpots, wettype transformers, diffusion pumps and in oil-filled heaters. Aerospace use includes the external coolant loop and radiators of the International Space Station Zvezda module, which rejects heat in the vacuum of space.

\section{Iron powder}

Iron powder has several uses; for example production of magnetic alloys and certain types of steels. 
Iron powder is formed as a whole from several other iron particles. The particle sizes vary anywhere from 20$200 \mu \mathrm{m}$. The iron properties differ depending on the production method and history of a specific iron powder. There are three types of iron powder classifications: reduced iron powder, atomized powder, and electrolyte iron powder. Each type is used in various applications depending on their properties. There is very little difference in the visual appearances of reduced iron powder and atomized iron powder.

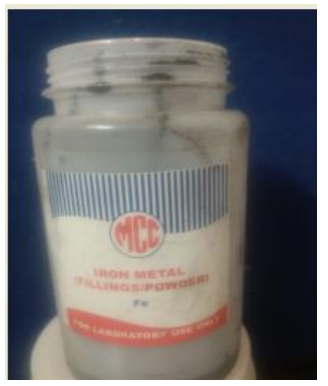

First we had pour $250 \mathrm{ml}$ silicone oil into glass container. after that taken iron power for making MR fluid. step by step we had added fine iron power to silicon oil and prepared MR fluid for project.

\section{PROJECT COMPONENT AND SPECIFICATION}

\section{MICROCONTROLLER:}

A microcontroller is a small computer on a single integrated circuit containing a processor core, memory, and programmable input/output peripherals. The one we used is Arduino Uno.

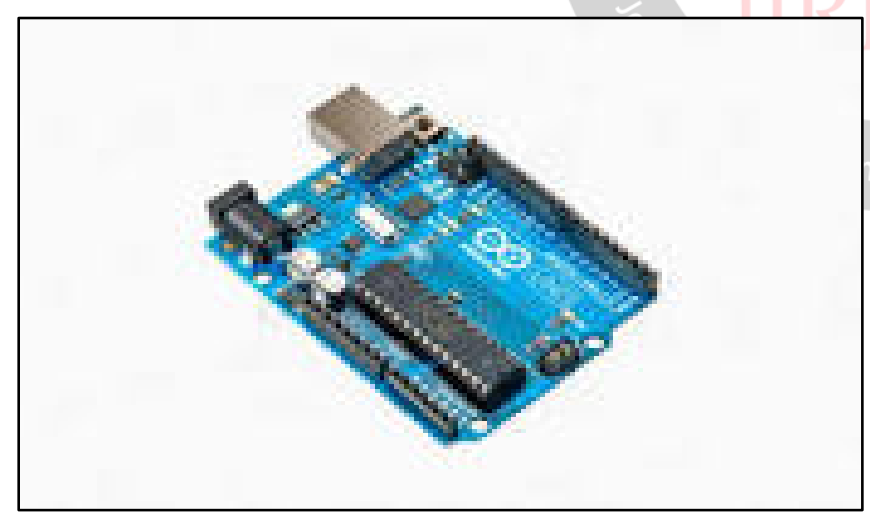

RELAY 5v:

Description The new KEYES 5V Relay Module is perfectly made for Arduino application. It has three pins, the VCC, GND and Signal. It can act as switch if the circuit and the load circuit have different supply voltage. It is commonly use if the load circuit is AC. It is a switch used to connect isolated connection from the circuit using a circuit signal. It has red LED that turns on every time the coil is energized or the signal pin has a high input.

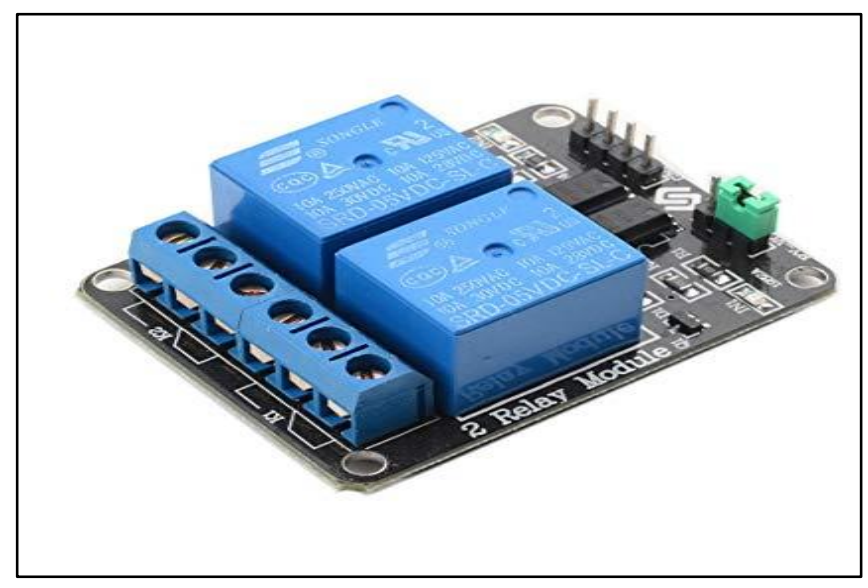

Specifications

- 5V - 12 V TTL control signal

- Maximum AC current and voltage : 10A 250VAC

- Maximum DC current and voltage : 10A 30VDC

- The control signal DC or AC, $220 \mathrm{~V}$ AC load can be controlled

- There is a normally open and one normally closed contact

- To make the coil of relay energized you must need to have an input of 1 in the signal pin.

\section{Pin Configuration}

$\bullet+: 5 \mathrm{~V}$ power supply

- - : Ground

- S : Signal from the Arduino

- NC : normally closed

- NO : normally open

- COMMON : common

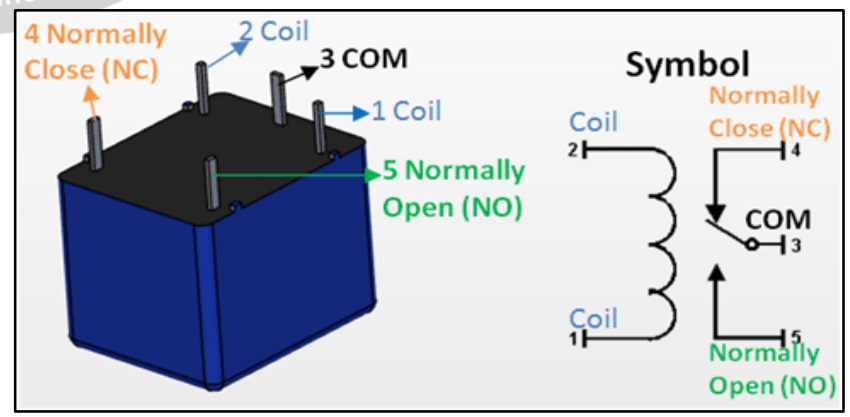

4X3 KEYPAD:

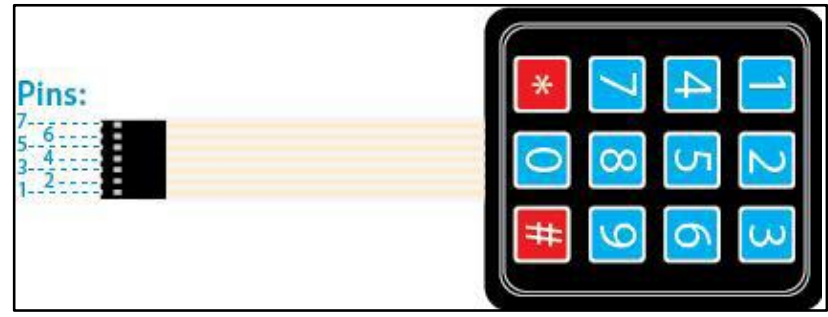




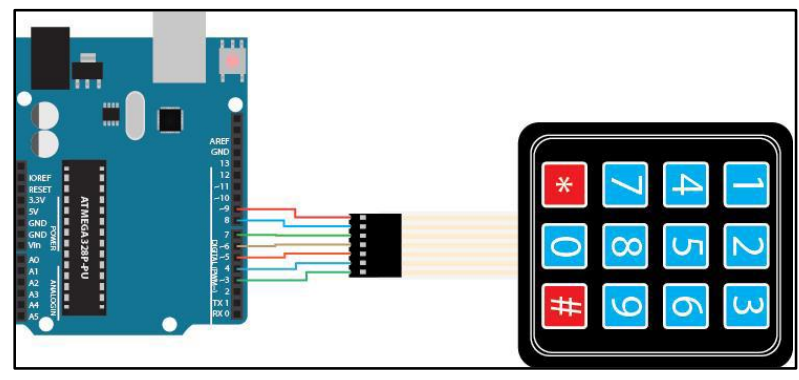

Most of the applications of embedded systems require keypads to take the user inputs, especially in case where an application requires more number of keys. With simple architecture and easy interfacing procedure, matrix keypads are replacing normal push-buttons by offering more inputs to the user with the lesser I/O pins. As a Human Machine Interface (HMI) keypad plays a major role in vital microprocessor and microcontroller based projects and equipments. Therefore, this article gives you a brief idea on matrix keypad interfacing with arduino microcontroller.

\section{WORKING OF PROJECT}

Project used Modify Yamaha FZ back shock absorber for set-up Once the suspension is locked into position using the mounting points of pneumatic cylinder, the coil input and output points was connected to a constant current source. Once the system is switched on, a constant current runs through the coil, this was generate magnetic field lines around the core (being the inner cylinder). Now this magnetic field lines will cause the iron particles within the fluid to align themselves with the field lines, intensifying the concentration of particles along those lines. This was cause the fluid to turn from a liquid to a semi--solid state and viscosity eventually increases. The increased viscosity results in increased resistance force at the piston during its motion, and hence leading to increased damping effect. The mode of operation would be squeeze valve mode. Valve mode is used around orifice in piston while squeeze mode will take place between top of piston and cylinder head.

\section{EXPERIMENTAL WORK}

\section{FFT analysis}

FFT is one main property in any sequence being used in general. To find this property of FFT for any given sequence, many transforms are being used. The major issues to be noticed in finding this property are the time and memory management. Two different algorithms are written for calculating FFT and Autocorrelation of any given sequence. Comparison is done between the two algorithms with respect to the memory and time managements and the better one is pointed. Comparison is between the two algorithms written, considering the time and memory as the only main constraints. Time taken by the two transforms in finding the fundamental frequency is taken. At the same time the memory consumed while using the two algorithms is also checked. Based on these aspects it is decided which algorithm is to be used for better results

\section{DEWE-43 Universal Data Acquisition Instrument}

When connected to the high speed USB 2.0 interface of any computer the DEWE-43 becomes a powerful measurement instrument for analog, digital, counter and CAN-bus data capture. Eight simultaneous analog inputs sample data at up to $204.8 \mathrm{kS} / \mathrm{s}$ and in combination with DEWETRON Modular Smart Interface modules ( MSI ) a wide range of sensors are supported Voltage Acceleration Pressure Force Temperature Sound Position RPM Torque Frequency Velocity And more The included DEWESoft application software adds powerful measurement and analysis capability, turning the DEWE-43 into a dedicated recorder, scope or FFT analyzer.

\section{Experimental Procedure}

- After completion of MR damper setup testing reading was taken.

- first we had applied constant pressure of 2 Bar to pneumatic cylinder of dimension $25 * 50$ on which damper was mounted.

- For applying constant force on MR damper Solenoid valve and Arduino Uno circuit was used.

- Then accelerometer was placed at output section of pneumatic cylinder on which MR damper was mounted and then reading of acceleration was taken.

- after that accelerometer shifted to the output section of MR damper plate and reading of acceleration was taken.

Final step we had applied constant current and voltage ( 12 volt and $2 \mathrm{Amp}$ ) to input coil of electromagnet. and above mentioned procedure was repeated.

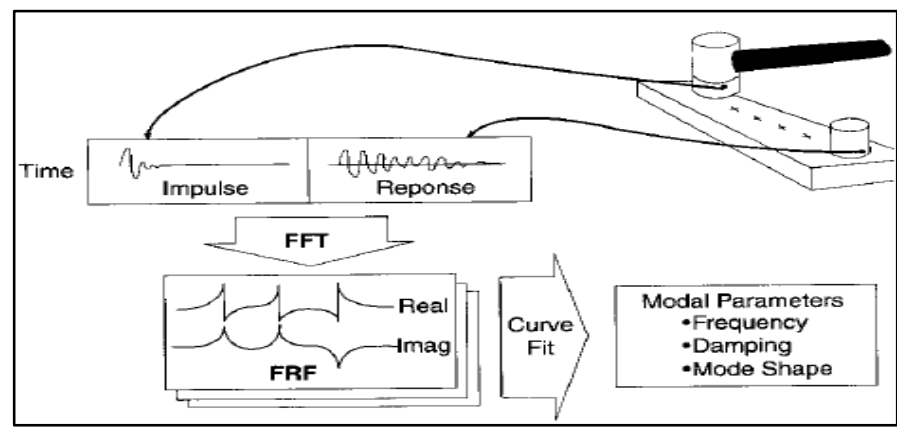

\section{Vibration sensors}

For standard measurements or modal analysis single axis I1T-50g-1 and isolated triaxial I3T-50G-1 IEPE cube accelerometer with $50 \mathrm{~g}$ range is recommended.

I1AI-500G-1 is a miniature accelerometer intended for measurement of higher vibration up to $500 \mathrm{~g}$. 
Accelerometers are equipped with TEDS smart sensor interface. DEWESoft software automatically detects the sensor and sets correct scaling.

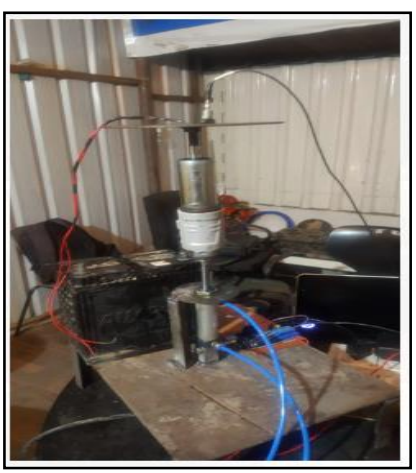

Fig Experimental testing setup

\section{RESULT}

\section{Reading at input section of MR damper plate}

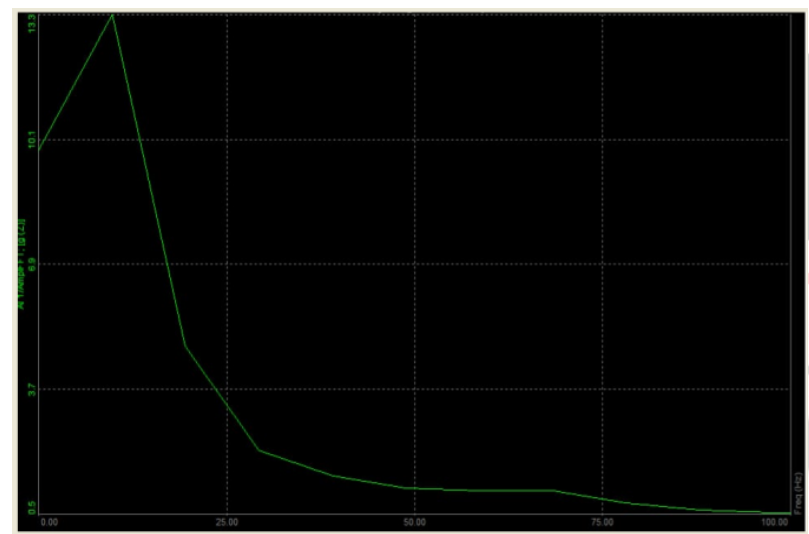

Fig Acceleration plot at output of pneumatic cylinder

Acceleration without electromagnet at MR damper input section was $13.3 \mathrm{~g}$

\section{Reading at output section of MR damper plate}

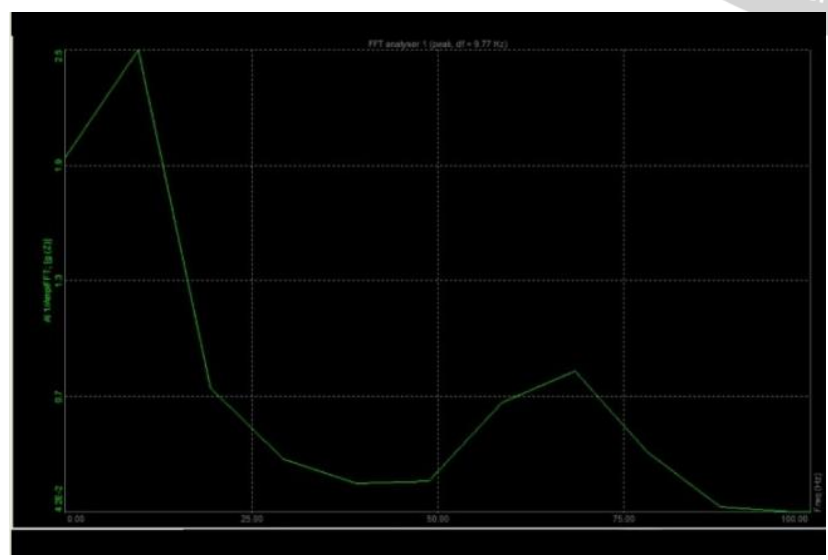

Fig Acceleration plot at output plate of MR damper without electromagnet

Acceleration without electromagnet at damper output was $2.5 \mathrm{~g}$

3. Reading at output section of MR damper plate with electromagnet

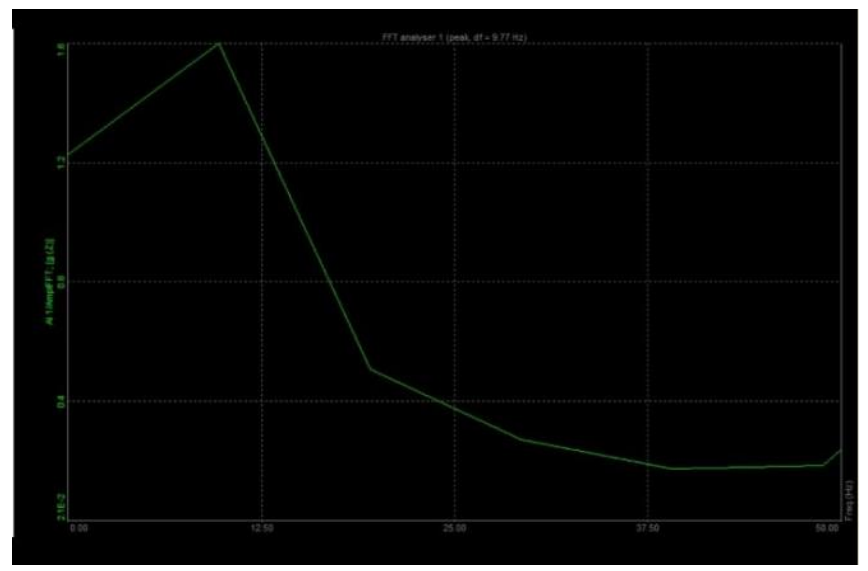

Fig Acceleration plot at output plate of MR damper with electromagnet

Acceleration with electromagnet at damper output was 1.6 $\mathrm{g}$

\begin{tabular}{|c|c|c|}
\hline Serial number & Condition & Acceleration \\
\hline 1 & $\begin{array}{c}\text { Acceleration with } \\
\text { electromagnet at } \\
\text { damper input }\end{array}$ & $13.3 \mathrm{~g}$ \\
\hline 2 & $\begin{array}{c}\text { Acceleration without } \\
\text { electromagnet at } \\
\text { damper output }\end{array}$ & $2.5 \mathrm{~g}$ \\
\hline 3 & $\begin{array}{c}\text { Acceleration with } \\
\text { electromagnet at } \\
\text { damper output }\end{array}$ & $1.6 \mathrm{~g}$ \\
\hline
\end{tabular}

\section{CONCLUSION}

1. For reduction of vibration used iron particle is more efficient as compare to use of magnetic fe3o4 iron particles on making of MR fluid.

2. MR Damper is mainly depended on magnetic flux density.

3. AS compare to conventional damper use of MR damper plays an important role in reducing the vibrations because, for every load condition the behavior of MR damper is change positively.

4. Due to use of MR fluid with electromagnet acceleration at output of damper is $1.6 \mathrm{~g}$ less than acceleration without electromagnet at damper output $2.5 \mathrm{~g}$.

5. AS compare to conventional damper use of MR damper plays an important role in reducing the vibrations because, for every load condition the behavior of MR damper is change positively.

\section{REFERENCES}

[1] BannaKasemi, Asan G. A. Muthalif, "Fuzzy-PID Controller for Semi-Active Vibration Control Using Magnetorheological Fluid Damper", Department of Mectronics Engineering, International Islamic University Malaysia, Gombak, Kuala Lumpur, 53100, Malaysia. 
[2] T.Imthiyaz Ahamed, R. Sundarrajan, "Implementation of Magneto-rheological dampers in bumpers of Automobiles for reducing impacts during accidents", Department of Mechanical Engineering, Sri Sairam Engineering College, West Tambaram, Chennai 600 044, India, vol. 97, 2014, pp. 1220 - 1226.

[3] Martin Oreny, SefanSegl, “Application of a magnetorheological damper and a dynamic absorber for a suspension of a working machine seat", Modelling of Mechanical and Mechatronic Systems, vol. 96, 2014, pp. $338-344$.

[4] Sadak Ali Khan, A.Suresh and N.Seetha Ramaiah, "Principles, Characteristics and Applications of Magneto RheologicalFluid Damper in Flow and Shear Mode", 3rd International Conference on Materials Processing and Characterisation (ICMPC 2014), vol. 6, 2014,pp. 1547 - 1556.

[5] Bhau K. Kumbhar, Satyajit R. Patil, "Synthesis and characterization of magneto-rheological (MR) fluids for MR brake application", Engineering Science and Technology, an International Journal, vol. 18, 2015, pp. 432-438.

[6] Suryawanshi Ravishankar, RayappaMahale, "A Study on Magneto Rheological Fluids and Their Applications", International Research Journal of Engineering and Technology (IRJET), vol. 02, 2015, pp.2395-0072.

[7] Harshal M. Bajaj, Gagandeep Singh Birdi, "Application of Magneto Rheological (Mr) Fluid Damper and Its Social Impact”, International Journal of Mechanical and Production Engineering, vol. 02, 2014, pp. 2320-2092.

[8] Fengchen Tu, Quan Yang, "Experimental Study and Design on Automobile Suspension Made of MagnetoRheological Damper”, Energy Procedia, vol. 16, 2012, pp. $417-425$.

[9] Avinasha B, Shyam Sundar S, "Experimental Study of Damping Characteristics of Air, Silicon Oil, Magneto Rheological Fluid on Twin Tube Damper", aDept. of Mechanical Engineering, National Institute of Technology- Karnataka, Suratkal - 575025, India, vol. 5, 2014, pp. $2258-2262$.

[10] Jie Wu, Lei Pei, Shouhu Xuan, "Experimental Particle Size Dependent Rheological Property In Magnetic Fluid", CAS Key Laboratory of Mechanical Behavior and Design of Materials, Department of Modern Mechanics, University of Science and Technological of China, Hefei 230027, People's Republic of China, vol0. 408, 2016, pp. 18-25. 